\title{
The Deep Freeze Redux: Cold Storage Packaging of Ektachrome Color Film
}

\author{
Lisa Palmer $\ddagger$ \\ ‡ Smithsonian Institution National Museum of Natural History, Washington, DC, United States of America
}

Corresponding author: Lisa Palmer (palmerl@si.edu)

Received: 09 Apr 2018 | Published: 04 Jul 2018

Citation: Palmer L (2018) The Deep Freeze Redux: Cold Storage Packaging of Ektachrome Color Film. Biodiversity Information Science and Standards 2: e25640. https://doi.org/10.3897/biss.2.25640

\begin{abstract}
At the 2017 SPNHC meetings in Denver, a five-minute Storage Techniques for Art, Science and History (STASH) talk was presented on the cold storage of film-based media. Herein, a more in-depth presentation of the Smithsonian's archival project with a status update is provided.

In February 2016 world-renowned ichthyologist John E. Randall (Jack) donated his 10,559 film-based slide collection of fishes to the Smithsonian Institution National Museum of Natural History (NMNH). Beginning in the 1970's, Jack used predominately $120 \mathrm{~mm}$ Ektachrome film to photograph marine fishes. The first-generation slides were stored in cool storage, approximately $40 \mathrm{~F} / 4.5 \mathrm{C}$, for much of their lives, thus preserving film color quite well as well as extending the life expectancy of film. Although digital surrogates of the slides have been created, the Division of Fishes intends to ensure the stabilization of the original color film by placing the slides in cold $(-4 \mathrm{~F} /-20 \mathrm{C})$ storage.

Color dyes used in Ektachrome slide film are fairly fugitive, and a known strategy to slow the rate of fading is to store slides in the coldest storage possible. NMNH Division of Fishes rehoused slides based on methods developed by the US National Park Service and the US National Gallery of Art. Prior to placing into cold storage, the slides were rehoused using archival supplies. The packaging methods we used are to prevent or reduce inherent deterioration as well as to help prevent any condensation buildup during the acclimation period that can occur when moving between quite differing temperature environments. In
\end{abstract}


this discussion, I will evaluate the processes and materials used as well as to reflect on post-mortem takeaways.

\section{Keywords}

cold storage, archival, supplies, rehousing, housing

\section{Presenting author}

Lisa Palmer 